\title{
Pressure Retarded Osmosis Process for Power Generation: Feasibility, Energy Balance and Controlling Parameters
}

\author{
Ali Altaee ${ }^{1}$, John Zhou ${ }^{1}$, Adnan Alhathal Alanezi ${ }^{2}$, Guillermo Zaragoza ${ }^{3}$
}

\author{
${ }^{1}$ School of Civil and Environmental Engineering, University of Technology Sydney, Ultimo, NSW 2007, \\ Australia \\ ${ }^{2}$ Department of Chemical Engineering Technology, College of Technological Studies, The Public Authority for \\ Applied Education and Training (PAAET), P.O. Box 117, Sabah AlSalem 44010, Kuwait \\ ${ }^{3}$ CIEMAT, Plataforma Solar de Almería, Ctra. de Senés s/n, 04200 Tabernas, Almería, Spain
}

\begin{abstract}
The feasibility of pressure-retarded osmosis (PRO) for power generation was evaluated with consideration of the energy inputs and losses in the process. The effects of the concentration polarization, reverse salt diffusion, and external resistance at the membrane porous layer were quantified, for the first time, along the membrane module to determine their contributions to the energy loss in the PRO process. Concentration polarization was responsible for up to $40 \%$ of the energy loss during the PRO process. However, increasing the PRO membrane modules from 1 to 4 resulted in a variable increase of the energy output depending on the salinity gradient. The energy requirements for draw and feed solution pretreatment were estimated to be over $38 \%$ of the total energy inputs. Results showed that coupling seawater (SW) with river water (RW) was unable to generate sufficient energy to compensate for the energy inputs and losses during the PRO process. With $0.39 \mathrm{kwh} / \mathrm{m}^{3}$ maximum specific energy in the PRO process, the energy yield of reverse osmosis brine (ROB)-wastewater (WW) salinity gradient was slightly greater than the total energy inputs, although using Dead Sea-SW/ROB salinity gradient was more promising. Overall, the primary current limitation is the lack of suitable PRO membranes that can withstand a high hydraulic pressure.
\end{abstract}

Keywords: Pressure-Retarded Osmosis, Renewable Energy, Salinity Gradient, Osmotic Energy, Hydraulic Energy

\section{Introduction:}

In the past decade, pressure-retarded osmosis (PRO) has been extensively investigated for power generation from salinity-gradient resources [1-7]. Numerous experimental studies have been performed to understand the process behavior, performance, and membrane efficiency for power generation from a salinity-gradient process. The process has been tested in a pilot plant to demonstrate its performance and feasibility in practical applications [8-10]. The results of the bench and pilot plant tests indicate that the process can be source of renewable energy, especially after the commercial development of a PRO membrane [10-12]. Recently, thermodynamic analysis of PRO process has revealed that the energy input may exceed the energy output because of an insufficient osmotic energy of the salinity gradient and energy losses due to membrane imperfection $[7,13]$. Therefore, the minimum energy requirements, including energy losses and pretreatment energy, should be identified. To date, lack of studies evaluating the exergy of the PRO system and limitations with regard to the type of salinity gradients and membrane inefficiencies are there and this 
has led to a gap in the research focus. Furthermore, most of the PRO experiments were performed on laboratory scale units which exaggerated the process performance. As such, the impact of PRO module length on the performance of PRO has been underestimated in the previous works.

The PRO process has been proposed for power generation using seawater (SW) and river water (RW) as a salinity-gradient resource. Power densities between 2.2 and $5.8 \mathrm{~W} / \mathrm{m}^{2}$ have been reported, depending on the membrane type and hydraulic pressure [14]. A power density of $5 \mathrm{~W} / \mathrm{m}^{2}$ was recommended for an economical PRO process based on a pilot plant test performed by Statkraft Company, Norway $[10,14]$. This value has not been commented on by recent pilot plant studies, therefore, still widely accepted in literature. SW-RW was investigated in a pilot plant by Statkraft; the pilot plant test was performed for few years and shut down in 2011 because of unsatisfactory performance [3]. There is little information available about the reasons for shutting down the Statkraft pilot plant, but it is considered that the energy efficiency was one of the main reasons. Reverse osmosis brine (ROB)wastewater (WW) salinity resources have been evaluated for power generation by the PRO process. Wan and Chung reported power densities of 6.6 and $8.9 \mathrm{~W} / \mathrm{m}^{2}$ for the Ultrafiltration (UF) and nanofiltration pretreatment of WW, respectively [16]. In a recent pilot plant study, Saito et al. used a Toyobo membrane and a ROB-WW salinity gradient and achieved a power density of $7.7 \mathrm{~W} / \mathrm{m}^{2}$; UF membrane was used for WW filtration [8]. Although ROB does not require pretreatment, no data have been reported regarding the energy requirements for the pretreatment of the feed solution. High-salinity draw solutions, such as Dead Sea (DS) and Salt Lake solutions, have been proposed for the PRO process. DS coupling with WW, SW, or RO brine would improve the PRO performance owing to the high energy potential of the salinity gradient. Theoretically, coupling DS water with $35 \mathrm{~g} / \mathrm{L} \mathrm{SW}$ water has the potential to increase the power density to $44 \mathrm{~W} / \mathrm{m}^{2}$, which is 8 times higher than the suggested threshold for an economical PRO process [17, 18]. A recent study for evaluating the process viability for power generation from the SW-RW salinity gradient showed that the power generated by the PRO process was lower than the energy required for the pumping and pretreatment of feed and draw solutions [13]. The maximum energy generated by SW-RW is $0.25 \mathrm{kWh} / \mathrm{m}^{3}$, whereas the maximum extractable energy by the PRO process is lower than that because of energy loss and membrane inefficiency. Furthermore, the energy required for the pretreatment and pumping was between 0.17 and $0.5 \mathrm{kWh} / \mathrm{m}^{3}$, which could be more than the maximum energy yield of the SW-RW salinity gradient [19, 20].

In the present study, we examined the energy efficiency of the PRO process for different salinity-gradient resources, considering the energy requirements for pretreatment and energy losses. Thermodynamically, PRO is feasible when the power output is higher than the power input; therefore, the power input was calculated including energy losses due the membrane imperfection, pretreatment of feeds, losses in pressure exchanger and due to pumping. The energy requirements for the pretreatment of the draw and feed solution were evaluated for several commonly used feed and draw solutions. The energy yield for an ideal membrane (no concentration polarization and reverse salt diffusion) was calculated and compared with that for a non-ideal PRO membrane (including concentration polarization and reverse salt diffusion). The underperformance of PRO process represented by concentration polarization, reverse salt diffusion, and external resistance of the support 
layer was quantified separately to identify their effects on the energy output of the PRO process. The energy input for the pretreatment and the energy losses were quantified for each salinity gradient investigated. We also estimated the extracted specific energy along the PRO membrane module for the multi-modules PRO system to identify the number of PRO membranes required in the PRO process for different type of salinity gradients. The computer model used in this study has already been validated using experimental data with more than $90 \%$ agreement $[2,6]$. The model accounts for the effects of internal and external concentration polarization and was further developed to include impacts of external resistance at membrane support layer. The findings of this study is to identify i) salinity gradients which have higher power output than power input due to membrane imperfection, losses and process pre-requirements and ii) key limitations of current PRO membrane to be considered in future studies on membrane fabrication.

\section{Energy yield and membrane module}

The energy yield of the salinity-gradient resource is affected by the membrane area and the feed characteristics along the PRO module, due to the dilution and concentration of the draw and feed solutions, respectively [6, 21]. For an ideal membrane, the membrane concentration polarization and reverse salt diffusion are ignored. Accordingly, the water flux, $J_{w}$, is estimated using the following equation $[13,15]$ :

$$
J_{w}=A_{w}(\Delta \pi-\Delta P),
$$

where $A_{w}$ is the membrane permeability ( $\left.\mathrm{L} / \mathrm{m}^{2} \mathrm{hbar}\right), \Delta \pi$ is the osmotic pressure gradient across the membrane (bar), and $\Delta P$ is the hydraulic pressure difference across the membrane (bar). For a non-ideal PRO process, the water flux is affected by the phenomena of concentration polarization and salt reverse diffusion, as follows [4]:

$$
J_{w}=A_{w}\left\{\frac{\pi_{D b} \exp \left(\frac{-J_{w}}{k_{d}}\right)-\pi_{F b} \exp \left(J_{w} K+\frac{J_{w}}{k_{f}}\right)}{1+\frac{B}{J_{w}}\left[\exp \left(\frac{J_{w}}{K}+\frac{J_{w}}{k_{f}}\right)-\exp \left(\frac{-J_{w}}{k_{d}}\right]\right.}-\Delta P\right\}
$$

where $\Delta \pi_{D b}$ and $\Delta \pi_{F b}$ are the bulk osmotic pressure of the draw and feed solutions, respectively (bar); $k_{d}$ and $k_{f}$ are the mass-transfer coefficients of the draw and feed solutions, respectively $(\mathrm{m} / \mathrm{h}) ; K$ is the solute resistivity in the case where the feed is facing the feed solution $(\mathrm{h} / \mathrm{m})$; and $B$ is the salt permeability coefficient $\left(\mathrm{L} / \mathrm{hm}^{2} \cdot\right.$ bar). Equation 2 predicts the membrane flux when the draw solution faces the membrane active layer (DS$\mathrm{AL})$, the PRO mode. It also accounts for the effect of external resistance ( $\mathrm{CPe}$ ) at the porous support layer which represented by $J_{w} / K_{f}$ parameter. The water flux changes along the PRO membrane because of the water permeation across the module; hence, $J_{w}$ and the concentrations of the feed and draw solutions along the PRO module should be calculated. This enables us to calculate the maximum specific energy generation by the PRO process from a salinity-gradient resource at any distance along the membrane module. At a distance $x$ along the PRO module, the bulk concentration of the draw solution, $C_{D b, x n}$, can be estimated as follows: 
$C_{D b, n x}=\frac{C_{D i, n x}+C_{D o, n x}}{2}$

where $C_{D i, n x}$ is the inlet concentration of the draw solution at the distance $x(\mathrm{M}), C_{D o, n x}$ is the outlet concentration of the draw solution at the distance $x(\mathrm{M})$, and $n$ is the number of PRO module in the pressure vessel. $C_{D o, n x}$ was calculated using the flow rate and mass-balance equation assuming the complete rejection of ions by the membrane, i.e., a reflection coefficient of unity:

$C_{D o, n x}=\frac{C_{D i, n x} Q_{D i, n x}}{Q_{D o, n x}}$

where $Q_{D i, n x}$ is the inlet flow rate of the draw solution $\left(\mathrm{m}^{3} / \mathrm{h}\right), C_{D i, n x}$ is the outlet concentration of the draw solution (M), and $Q_{D o, n x}$ is the outlet concentration of the draw solution (mg/L). Equation 3 can be re-written using Equation 4 to express $C_{D o, x n}$ :

$C_{D b, n x}=\frac{C_{D i, n x}\left(1+\frac{Q_{D i, n x}}{Q_{D o, n x}}\right)}{2}$

At a distance $x$ along the PRO module, $Q_{D o, n x}$ is equal to the sum of the inlet flow rate of the draw solution and the water permeation flow rate $\left(Q_{p, n x}\right)$; i.e. $Q_{D o, n x}=Q_{D i, n x}+Q_{p, n x}$. By applying the same method to the feed side, the bulk concentration of the feed solution at a distance $x$ along the PRO module was calculated as follows:

$C_{F b, n x}=\frac{C_{F i, n x}\left(1-\frac{Q_{F i n n x}}{Q_{F o, n x}}\right)}{2}$

Here, $Q_{F o, x n}$ is the difference between the inlet feed flow rate and the permeation flow; i.e., $Q_{F o, n x}=Q_{F i, n x}-Q_{p, n x}$. Assuming that the Van't Hoff equation is valid for the concentration of the feed and draw solutions in Equations 5 and 6, by substituting in Equation 2, we obtain

$$
J_{w, n x}=A_{w}\left(\frac{\left(\phi R T C_{D i, n x}\left(1+\frac{Q_{D i, n x}}{Q_{D o, n x}}\right) / 2\right) \exp \left(\frac{-J_{w}}{k_{d}}\right)-\left(\phi R T C_{F i, n x}\left(1-\frac{Q_{F i, n x}}{Q_{F o, n x}}\right) / 2\right) \exp \left(J_{w} K+\frac{J_{w}}{k_{f}}\right)}{1+\frac{B}{J_{w-x}}\left(\exp \left(J_{w} K+\frac{J_{w}}{k_{f}}\right)-\exp \left(\frac{-J_{w}}{k_{d}}\right)\right)}-\Delta P\right)
$$

Here, $\Phi$ is number of ions in the solution, $R$ is the gas constant, and $T$ is the temperature in Kelvin. $A_{w}$ and $B$ were assumed to be $1.23 \mathrm{~L} / \mathrm{hm}^{2}$. bar and $2.6 \mathrm{~kg} / \mathrm{hm}^{2}$ respectively, $K_{d}=k_{f}=$ $0.18 \mathrm{~m} / \mathrm{h}$, and $K=31 \mathrm{~h} / \mathrm{m} \mathrm{[4]}$. $C_{D o, n x}$ and $C_{F o-n x}$ were then calculated using the equation for the bulk concentration of the draw and feed solutions, respectively. A recent study 
suggested a formula for estimating the maximum specific energy generation by the PRO [22]; for a PRO operating in the PRO mode (DS-AL), the expression is:

$$
E_{\max }=\frac{n R T\left(C_{D}-C_{F}\right)^{2}}{4\left(C_{D}-C_{F}\right)}
$$

where $C_{D}$ and $C_{F}$ are the concentrations of the draw and feed solutions, respectively (M), and $E_{\max }$ is the maximum specific energy $\left(\mathrm{kWh} / \mathrm{m}^{3}\right)$. Equation 8 describes the $E_{\max }$ of the inlet and outlet solutions; for the PRO module, the local $E_{\max }$ along the PRO module can be calculated by replacing the local concentrations of the draw and feed solutions according to the following equation:

$$
E_{\max , x}=\frac{n R T\left(C_{D, n x}-C_{F, n x}\right)^{2}}{4\left(C_{D, n x}-C_{F, n x}\right)}
$$

where $E_{m a, x}$ is the maximum specific energy at the distance $x\left(\mathrm{kWh} / \mathrm{m}^{3}\right)$, and $C_{D, n x}$ and $C_{F, n x}$ are the concentrations of the draw and feed solutions, respectively, at the distance $x(\mathrm{M})$. Equation 9 allows us to track the specific energy generation by the process along the PRO module. Reverse salt diffusion (RSD) is an intrinsic property of osmotically driven membrane processes that adversely impacts the performance of the membrane during the PRO process. The reverse salt flux, $J_{s}$, in the PRO process can be estimated using the following equation [13]:

$$
J_{s}=B\left(\frac{C_{D b} \exp \left(\frac{-J_{w}}{k}\right)-C_{F b} \exp \left(J_{w} K\right)}{1+\frac{B}{J_{w}}\left(\exp \left(J_{w} K\right)-\exp \left(\frac{-J_{w}}{k}\right)\right)}\right)
$$

Here, $B$ is the salt permeability coefficient $\left(\mathrm{L} / \mathrm{hm}^{2} \cdot\right.$ bar), and $C_{D b}$ and $C_{F b}$ are the bulk concentrations of the draw and feed solutions, respectively $(\mathrm{g} / \mathrm{L})$. The reverse salt flux along the PRO module was calculated in order to elucidate its impact on the performance of the PRO process. The expression used to calculate the reverse salt flux along the membrane, $J_{s, n x}$ is

$$
J_{s, n x}=B\left(\frac{C_{D b, n x} \exp \left(\frac{-J_{w, n x}}{k}\right)-C_{F b, n x} \exp \left(J_{w, n x} K\right)}{1+\frac{B}{J_{w, n x}}\left(\exp \left(J_{w, n x} K\right)-\exp \left(\frac{-J_{w, n x}}{k}\right)\right)}\right)
$$

For simplicity, $J_{s, x n}$ was expressed in molar concentration throughout this study.

\section{Extractable specific power generation}

The power density, $W_{n x}$, represents the power generation per unit area of the PRO membrane and was estimated along the PRO module according to the following equation: 
$W_{n x}=P^{*} J_{w, n x}$,

where $W_{n x}$ is the power density at the distance $x$ along the PRO module $\left(\mathrm{W} / \mathrm{m}^{3}\right), P$ is the hydraulic pressure on the draw-solution side of the membrane (bar) and $J_{w, n x}$ was calculated using equation 7.

Four salinity-gradient resources were evaluated; DS-SW, DS-ROB, SW-RW, and ROB-WW; and the results were obtained at $\Delta P=\Delta \pi / 2$ (Figure 1). DS draw solution coupling with SW or ROB forms salinity gradients in which considerable internal and external concentration polarizations are operating during the PRO process whereas only external concentration polarization is operating during the PRO process for SW-RW and ROB-WW salinity gradients. A 1 meter long PRO module was assumed, and there are four PRO modules in the pressure vessel to study the effect of increasing membrane modules on the process performance. Average power density for each module was calculated and compared with the minimum theoretical value of $5 \mathrm{~W} / \mathrm{m}^{2}$ which has been suggested for an economic PRO process [Figure $1 \mathrm{~A}]$. It is worth mentioning that $W_{\min }$ is the minimum theoretical value of power density for an economic PRO process. The average power density values decreased in the following order: DS-SW > DS-ROB > ROB-WW > SW-RW. This was due to the higher osmotic pressure across the membrane in the case of DS draw solution which yielded a larger power density for the PRO process. The average power density for DS-SW and DS-ROB salinity gradients was higher than the minimum threshold value of $5 \mathrm{~W} / \mathrm{m}^{2}$ for all PRO modules, except module 4 of DS-ROB in which the power density was $4.8 \mathrm{~W} / \mathrm{m}^{2}$. For ROB-WW salinitygradient, the power density was higher than $5 \mathrm{~W} / \mathrm{m}^{2}$ for PRO modules one to three but it was less than $5 \mathrm{~W} / \mathrm{m}^{2}$ for the fourth PRO modules; $3.6 \mathrm{~W} / \mathrm{m}^{2}$. For SW-RW salinity gradient, the average power density was less than $5 \mathrm{~W} / \mathrm{m}^{2}$ for all PRO modules; this is an indicator of insufficient osmotic energy to produce enough power. In general, the average power density decreased from the first to the fourth PRO module due to osmotic energy extraction by the PRO process. As such, the extracted osmotic energy in the PRO process was calculated as the difference between the inlet and outlet maximum specific energies for any section along the membrane, as follows:

$$
E_{e x t, x}=\frac{n R T\left(C_{D i, n x}-C_{F i, n x}\right)^{2}}{4\left(C_{D i, n x}-C_{F i, n x}\right)}-\frac{n R T\left(C_{D o, n x}-C_{F o, n x}\right)^{2}}{4\left(C_{D o, n x}-C_{F o, n x}\right)},
$$

where $E_{\text {ect }, x}$ is the extracted energy along the membrane $\left(\mathrm{kWh} / \mathrm{m}^{3}\right)$. Figure $1 \mathrm{~B}$ shows the extracted specific energy along the PRO modules. $E_{\text {ect }, x}$ reached $0.054 \mathrm{kWh} / \mathrm{m}^{3}$ at $0.1 \mathrm{~m}$ of the first module for the DS-SW salinity-gradient resource but was lower for the other salinity-gradient resources: $0.037,0.009$, and $0.003 \mathrm{kWh} / \mathrm{m}^{3}$ for the DS-ROB, ROB-WW, and SW-RW salinity gradients, respectively. A sharp decrease in the extracted specific energy was observed for the DS-SW and DS-ROB salinity gradients, whereas a moderate decrease of the extracted specific energy was observed for the ROB-WW and SW-RW salinity gradients. This was due to the high water flux in the cases of the DS-SW and DS-ROB salinity gradients, which resulted in the rapid dilution of the draw solution. The first PRO module was responsible for most energy recovery from DS-SW salinity gradient. More than $57 \%$ of the extracted energy of the DS-SW salinity gradient occurred in the first PRO module, which was responsible for the sharp decrease in the extracted specific energy (Figure 1B). To a slightly 
lesser extent, the first PRO module contributed $55 \%$ of the extracted specific energy of the DS-ROB salinity gradient. The energy yield of the first PRO module was approximately $39 \%$ for the SW-RW salinity gradient, indicating the lower driving force across the PRO membrane in this case. The percentage of the extracted specific energy decreased in the subsequent PRO modules; especially in case of DS-SW and DS-ROB salinity gradients. This was because of the external concentration polarization and the impact of the internal concentration polarization at the feed side, which reduced the driving pressure across the membrane. The percentages of extracted energy for the fourth PRO module were $15 \%$, $11 \%, 7 \%$, and $6 \%$ for the salinity gradients SW-RW, ROB-WW, DS-ROB, and DS-SW, respectively. The contribution of fourth PRO module of the ROB-WW and SW-WW salinity gradients was lower than that of DS-SW and DS-ROB due to the lower osmotic driving force.

The reverse salt diffusion was estimated along each PRO module in the PRO process (Figure 2). Ignoring the membrane fouling, reverse salt diffusion has an adverse impact on the performance of the PRO process and increases the salt concentration on the feed side. Unfortunately, this phenomenon is more serious at high draw-solution concentrations. Practically, the energy yield of a salinity-gradient resource increases with the draw-solution concentration, accompanied by the increase of the reverse salt diffusion across the membrane. As shown in Figure 2, the reverse salt diffusion reached $8.2 \times 10^{-3} \mathrm{~mol} / \mathrm{m}^{2} \mathrm{~h}$ in the first module of the DS-SW salinity gradient and decreased to $6.8 \times 10^{-3}, 2.7 \times 10^{-3}$, and $1.4 \times 10^{-3} \mathrm{~mol} / \mathrm{m}^{2} \mathrm{~h}$ for the DS-ROB, ROB-WW, and SW-RW salinity gradients, respectively. Apparently, the reverse salt diffusion of the DS-SW was almost 6 times higher than that of the SW-RW salinity gradient. Furthermore, the results reveal that the reverse salt diffusion decreased along the membrane in the consecutive modules owing to the dilution of the draw solution. Therefore, its impact was more notable in the first PRO module and decreased in the subsequent modules. This problem affected the extracted energy for the first PRO module, in which the concentration of the draw solution was the highest and could be mitigated by using a first PRO module with higher rejection than the other PRO modules in the pressure vessel. This suggestion will, probably, reduce the back diffusion of the drawsolution to the feed side in the first module. However, this is out of the scope of this study and should be investigated in a separate study. 

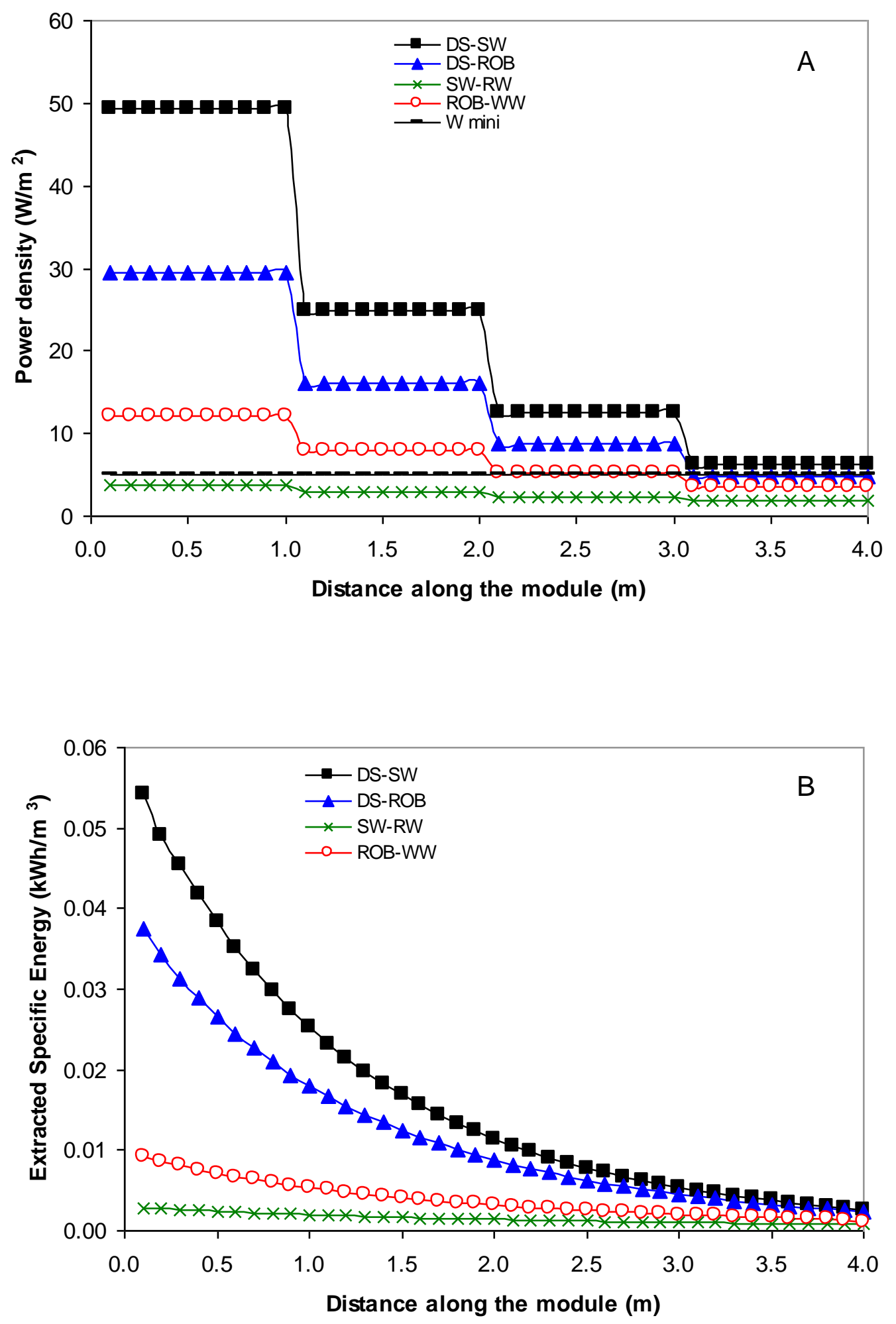

Figure 1: PRO process performance for four salinity-gradient resources: DS-SW, DS-ROB, ROB-WW, and SW-WW; A) power density along the four PRO modules of the PRO system, B) extracted specific energy for the four modules of the PRO system, in the $x$-axis each 1 meter is equal to the a full PRO module 


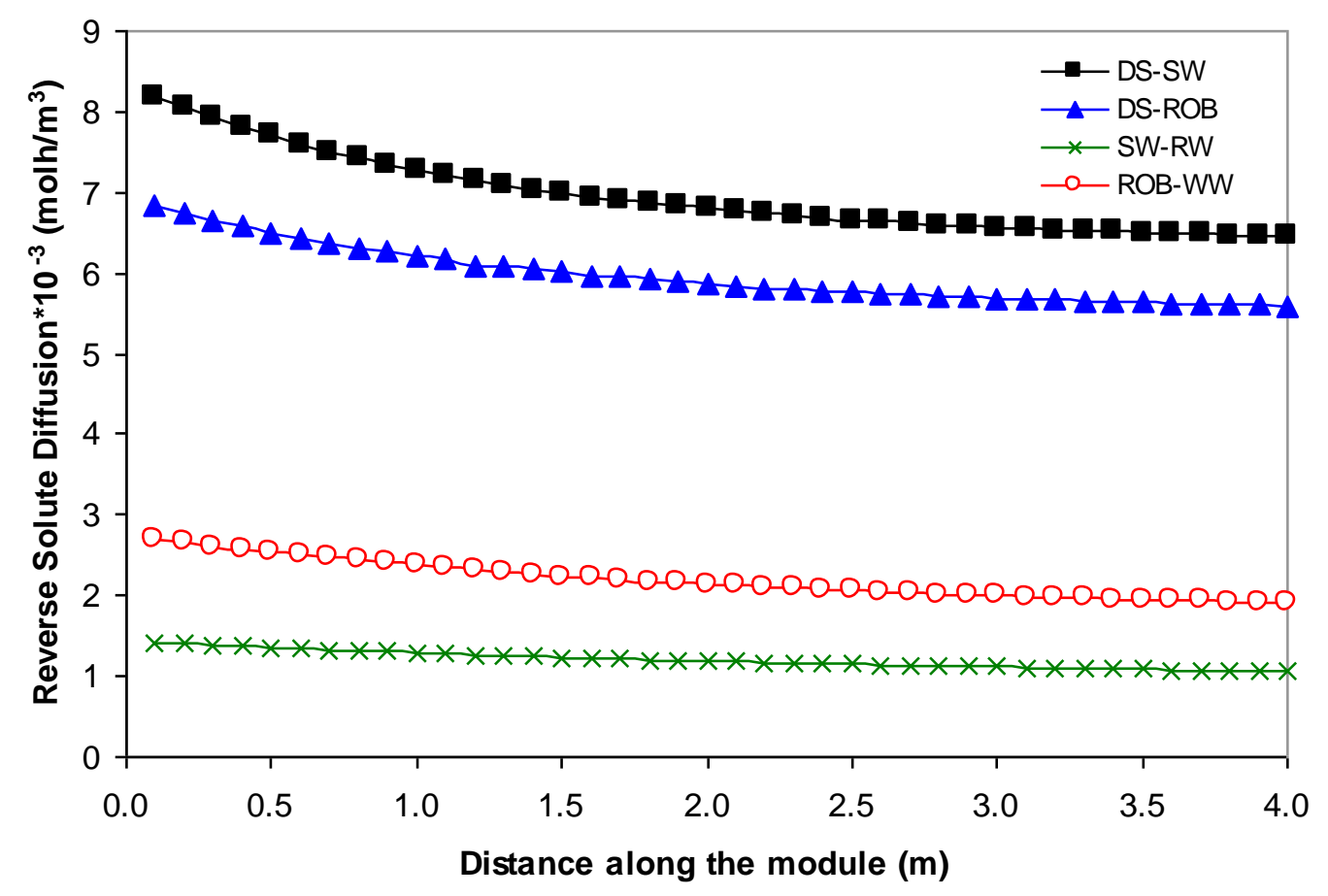

Figure 2: Reverse salt diffusion of each module in the PRO system, each 1 meter on the $x$ axis is a full PRO module

\section{Impact of PRO membrane imperfection on power generation}

The membrane-intrinsic properties manifested by the concentration polarization and reverse salt diffusion affect the performance of the PRO process and reduce the amount of potential energy that can be harvested. Several studies have investigated the effect of the concentration polarization and reverse salt diffusion on the performance of PRO [4, 22-24], but no study has quantified this effect along the membrane module for different salinitygradient resources. In the current study, the accumulative extracted energy, defined as the harvested energy increase along the PRO module, was calculated for: i) the ideal PRO process without concentration polarization (CP) and RSD effects (model 1), ii) PRO process with $\mathrm{CP}+\mathrm{CPe}+\mathrm{RSD}$ effects (model 2 ), iii) the RO process with $\mathrm{CP}+\mathrm{CPe}$ effects only (model 3 ), and iv) the PRO process with CP+RSD effects (model 4). Eect,x was calculated and the accumulative specific energy is equal to the sum of $E_{\text {ect }, x}$ along the PRO membrane module. Table 1 shows the mathematical expressions used in the calculation of the membrane flux for models 1 to 4 . Two to four PRO modules-each assumed to be $1 \mathrm{~m}$ long-were packed in the pressure vessel and the accumulative specific energy was calculated for each salinity gradient resource.

In this section, the accumulative specific energy was calculated for each model-1 to 4-as shown in Table 2. Only two PRO modules per pressure vessel were considered in the case of DS-SW and DS-ROB salinity gradients and Model 1 because of the sharp decrease in the water flux at the end of the second PRO module. The large water flux across the first PRO module resulted in the dilution of draw solution and a sharp drop of the osmotic driving force. The hydraulic pressure was equal to $\Delta \pi / 2$ for all the salinity-gradient resources. In 
general, the accumulative specific energy increased along the PRO modules in the pressure vessel and reached the highest level in the case of the DS-SW salinity gradient owing to the considerable osmotic driving force across the membrane [Figure 3]. The effect of $\mathrm{CP}+\mathrm{CPe}+\mathrm{RSD}$ was calculated as the difference between model 1 and model 2 [Table2]. For the DS-SW salinity gradient, the accumulative specific energy calculated using model 1 increased almost linearly at the beginning of the first PRO module and then leveled out in the second PRO module [Figure 3A]. Comparing the accumulative specific energy along the first PRO module using models 1 and 2 reveals that $C P+C P e+R S D$ was responsible for the $51 \%$ loss of the energy yield. The percentage of the energy loss due to CP+CPe+RSD decreased to $32 \%$ in the second PRO membrane module, which suggests that, the specific energy loss due to this effect decreases in the consecutive PRO modules in the pressure vessel due to the lower osmotic driving force. Notably, $96 \%$ of the osmotic energy was extracted by the first PRO module for model 1 compared with $57 \%$ for model 2 , indicating the faster specific energy extraction of model 1 in the absence of concentration polarization and reverse salt diffusion effects. Although model 2 uses four PRO modules, the energy yield of the PRO system was $18 \%$ lower than that of two-module PRO system in model 1 . The results also indicate that more PRO modules are required in the non-ideal PRO process to achieve the desirable energy yield. In the case of DS-ROB salinity-gradient resource, the accumulative specific energy of model 1 and 2 is illustrated in Figure 3B. Comparing the energy yield in model 1 and 2 shows that the former model produced $15 \%$ more energy despite it uses only 2 PRO modules. For SW-RW salinity gradients, the accumulative specific energy calculated using models 1 and 2 increased gradually along PRO modules 1 to 4 (Figures 3C). The energy yield of four-module PRO system was 0.073 and $0.061 \mathrm{kWh} / \mathrm{m} 3$ according to models 1 and 2, respectively, which is a difference of only $17 \%$. Thus, the difference between model 1 and model 2 decreased by increasing the number of PRO modules in the pressure vessel. Similarly, for the ROB-WW salinity-gradient resource [Figure 3D], the difference between models 1 and 2 was $30 \%$ at the end of the first PRO module but decreased to $20 \%$ for the four-module PRO system. The results show that the effect of $\mathrm{CP}+\mathrm{CPe}+\mathrm{RSD}$ was more severe at higher concentrations of draw and feed solutions; i.e. DSROB $>$ DS-SW $>$ ROB-WW $>S W$-RW. Furthermore, the non-ideal PRO process (model 2) requires larger number of PRO modules than the ideal PRO process (model 1) for energy extraction from a salinity gradient resource.

The effect of $\mathrm{CP}+\mathrm{CPe}$ on the accumulative specific energy of PRO process was evaluated according to the difference between models 1 and 3 (Table 2). In the case of DS-SW salinity gradient, the difference in the total accumulative specific energy between model 1 and 3 was $24 \%$ at the end of second PRO module but decreased to $6 \%$ by increasing the PRO modules to four in model 3 . This confirms the abovementioned findings that non-ideal PRO process requires more PRO modules than ideal PRO process to overcome the effects of membrane imperfection. For the DS-ROB salinity gradient resource, the energy yield of fourmodule PRO system in model 3 was $6.5 \%$ lower than that of two-module PRO system in model 1 . The calculated energy yield using model 3 was $16 \%$ and $11 \%$ lower than that using model 1 for the SW-RW and ROB-WW salinity gradients, respectively (Table 2). The impact of $\mathrm{CP}+\mathrm{CPe}$ on the performance of PRO process was in the following order: DS-ROB $>\mathrm{DS}$ $S W>S W-R W>R O B-W W$. This was due to the high concentration of feed and draw solution in the DS-ROB salinity gradient which intensified the adverse impact of CP. 
The effect of RSD was equal to the difference between the accumulative specific energies calculated using models 2 and 3. For the DS-SW salinity gradient resource, the impact of RSD on the performance of PRO was much lower than that of the concentration polarization [Figure 3A]. RSD resulted in $13.5 \%$ loss in the energy yield of four-module PRO system according to the difference between model 2 and 3 . It increased gradually from module 1 to 4 due to the higher concentration of draw solution at the membrane surface caused by low water flux in the fourth PRO module. RSD phenomenon in the DS-ROB salinity gradient resource caused $9.5 \%$ decrease in the energy yield of the PRO system [Table 2]. On the contrary to the DS-SW salinity gradient, the impact of RSD decreased from PRO module 1 to 4 due to the higher concentration of feed solution in the DS-ROB salinity gradient. It should be noted that salt diffusion across the membrane is induced by the concentration difference between feed and draw solution at the membrane surface. The impact of RSD on the extracted energy from the SW-RW salinity gradient resource was insignificant; <1\% [Table 2]. The low concentration of SW draw solution caused this insignificant RSD effect. For the ROB-WW salinity gradient resource, RSD resulted in $10.5 \%$ reductions in the accumulative specific energy of the PRO process, as anticipated by the difference between models 2 and 3. In general, the impact of RSD on the performance of PRO process was lower than that of CP with largest impact was in the case of the DS-SW draw solution followed by DS-ROB, ROB-WW and SW-RW salinity gradients respectively.

The impact of CPe on the accumulative specific energy was calculated according to the difference between models 2 and 4 [Table 2]. In the case of DS-SW salinity gradient resource, a small decrease of the accumulative specific energy, about 5.5\%, was incurred due to CPe. This effect, however, was lower than the CP and RSD effects, as shown in Table 2. The effect of CPe caused 3\% loss of the accumulative specific energy at the end of the fourth PRO module of the DS-ROB salinity gradient. For the SW-RW salinity gradient resource, $\mathrm{CPe}$ had a trivial impact on the extracted osmotic energy because of the low feed concentration [Figure 3C]. Similarly, $\mathrm{CPe}$ caused $3 \%$ loss of the accumulative specific energy in the PRO system of the ROB-WW salinity gradient [Table 2]. In general, the effect of CPe on the performance of PRO process was lower than that of the CP and RSD which agrees with the previous studies [5]. The effects of $C P, C P e$ and RSD on the PRO process performance were in the following order: $C P+R S D+C P e>C P+C P e>R S D>C P e$.

Concentration polarization, $\mathrm{CP}$, parameters was responsible for the most energy loss in $\mathrm{CP}+\mathrm{CPe}$ calculations; it can be roughly estimated as the difference between the $\mathrm{CP}+\mathrm{CPe}$ and CPe parameters in Table 2. In effect, CP caused up to $40 \%$ loss in the extracted energy in the case of DS-SW salinity gradient. The results show that increasing PRO modules from 1 to 4 in the pressure vessel resulted in an increase in the specific energy output and decreased the difference between ideal and non-ideal PRO process. The percentage of the CP, CPe, and RSD reductions was dependent on the type of salinity-gradient resource. Concentration polarization effects was larger for salinity gradients of high feed and draw solution concentrations; i.e. DS-ROB. RSD and $\mathrm{CPe}$, respectively, had lower impact on the extractable osmotic energy than CP alone. The effect of RSD on the PRO performance was circa $1 \%$ for SW-RW but increased to $13.4 \%$ for the DS-SW Salinity gradient. Overall, membrane imperfection represented by concentration polarization and reverse salt diffusion not only affecting the performance of PRO process but also led to an increase of the membrane modules required in the PRO process. Practically, using multi PRO modules packed in a 
pressure vessel or large membrane area, such as hollow fiber PRO membrane, would reduce the impacts of the CP and RSD.
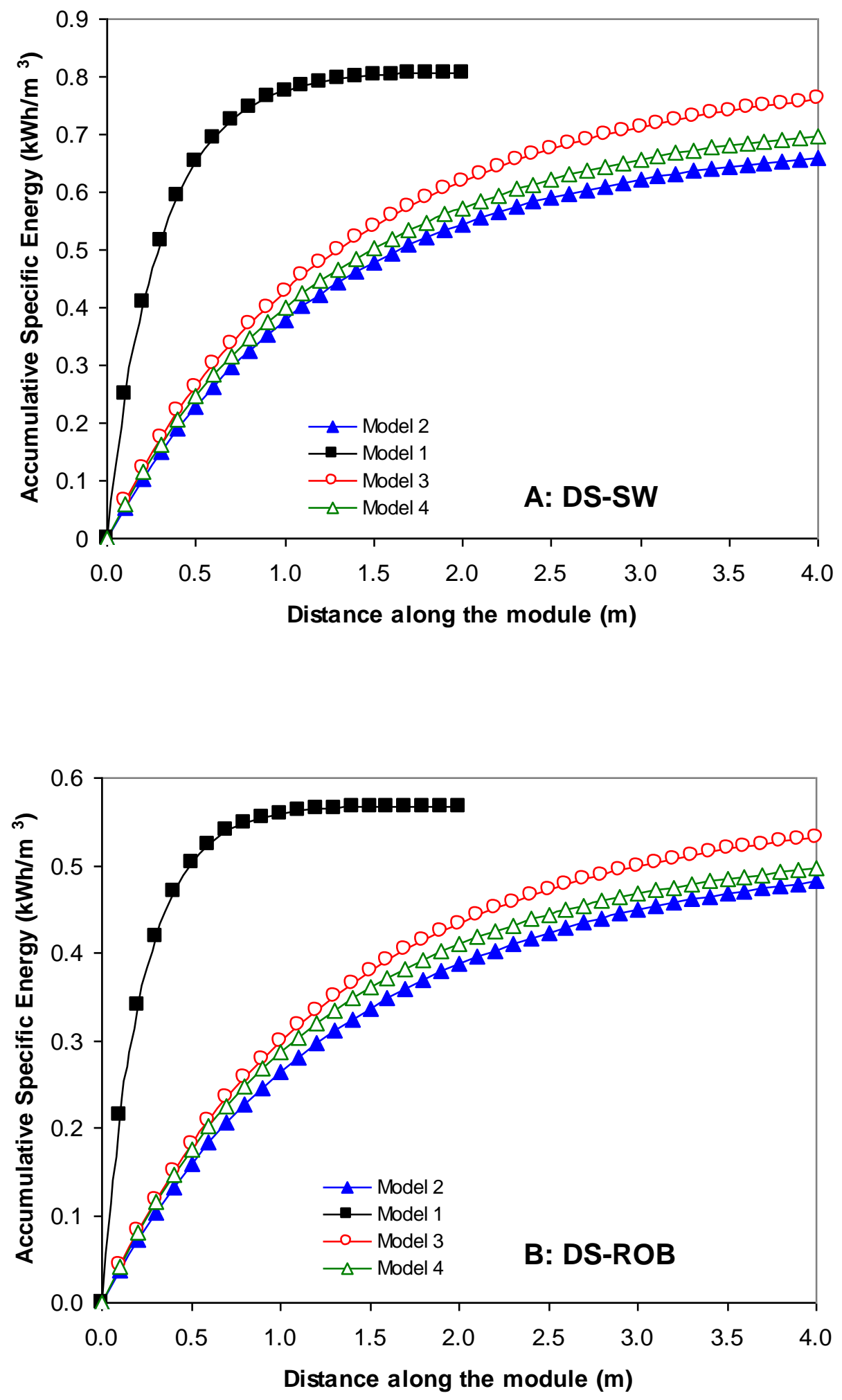

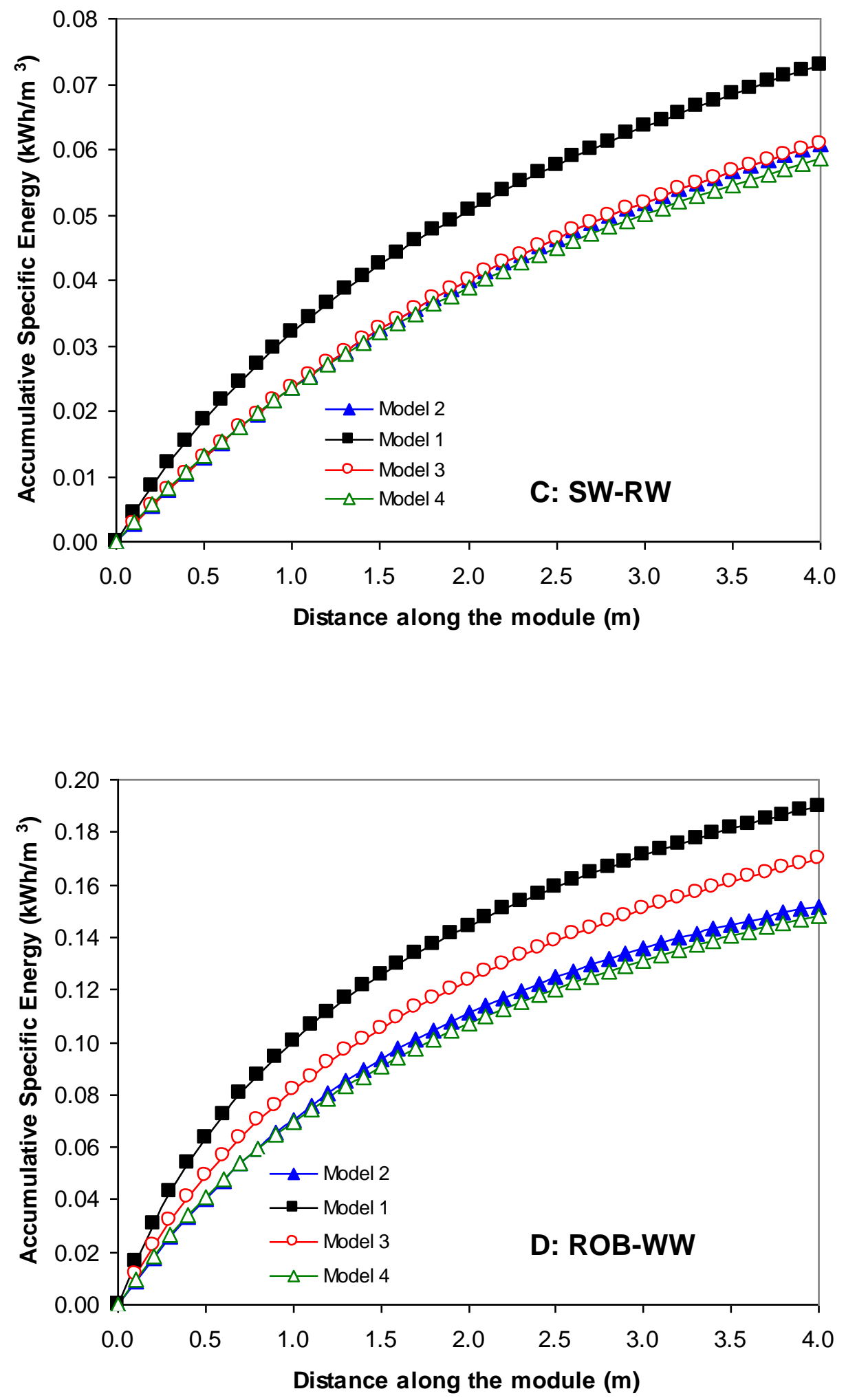

Figure 3: Impact of the membrane concentration polarization and reverse salt diffusion on the PRO process for ideal and existing membranes A) DS-SW salinity gradient B) DS-ROB salinity gradient C) SW-RW salinity gradient C) ROB-WW salinity gradient 
Table 1: Impact of the concentration polarization and reverse salt diffusion on the specific power generation by the PRO process; the effect of the external concentrative concentration polarization of the support layer was considered in the calculation of the concentration polarization, two PRO modules in the pressure vessel for DS-SW and DS-ROB salinity gradients in model 1 and four PRO modules in the pressure vessel for DS-SW, DSROB, ROB-WW, and SW-RW salinity gradients in models 1 to 4 .

\begin{tabular}{|c|c|c|}
\hline Model & Parameter & Expression \\
\hline 1 & $\begin{array}{c}\text { Ideal } \\
\text { membrane }\end{array}$ & $J_{w, x n}=A_{w}\left[\left(n R T C_{D i, x n}\left(1+\frac{Q_{D i, x n}}{Q_{D o, x n}}\right) / 2\right)-\left(n R T C_{F i, x n}\left(1-\frac{Q_{F i, x n}}{Q_{F o, x n}}\right) / 2\right)-\Delta P\right]$ \\
\hline 2 & $\begin{array}{c}\mathrm{CP}+\mathrm{CPe}+\mathrm{RSD} \\
{[4]}\end{array}$ & $J_{w, x n}=A_{w}\left(\frac{\left(n R T C_{D i, x n}\left(1+\frac{Q_{D i, x n}}{Q_{D o, x n}}\right) / 2\right) \exp \left(\frac{-J_{w}}{k_{d}}\right)-\left(n R T C_{F i, x n}\left(1-\frac{Q_{F i, x n}}{Q_{F o, x n}}\right) / 2\right) \exp \left(J_{w} K+\frac{J_{w}}{k_{f}}\right)}{1+\frac{B}{J_{w-x}}\left(\exp \left(J_{w} K+\frac{J_{w}}{k_{f}}\right)-\exp \left(\frac{-J_{w}}{k_{d}}\right)\right)}\right)$ \\
\hline 3 & $\begin{array}{c}\mathrm{CP}+\mathrm{CPe} \\
\text { this study }]\end{array}$ & $J_{w, x n}=A_{w}\left[\left(n R T C_{D i, x n}\left(1+\frac{Q_{D i, x n}}{Q_{D o, x n}}\right) / 2\right) \exp \left(\frac{-J_{w}}{k_{d}}\right)-\left(n R T C_{F i, x n}\left(1-\frac{Q_{F i, x n}}{Q_{F o, x n}}\right) / 2\right) \exp \left(J_{w} K+\frac{J_{w}}{k_{f}}\right)-\Delta P\right]$ \\
\hline 4 & $\begin{array}{c}\mathrm{CP}+\mathrm{RSD} \\
{[31]}\end{array}$ & $J_{w, x n}=A_{w}\left(\frac{\left.n R T C_{D i, x n}\left(1+\frac{Q_{D i, x n}}{Q_{D o, x n}}\right) / 2\right) \exp \left(\frac{-J_{w}}{k_{d}}\right)-\left(n R T C_{F i, x n}\left(1-\frac{Q_{F i, x n}}{Q_{F o, x n}}\right) / 2\right) \exp \left(J_{w} K\right)}{1+\frac{B}{J_{w-x}}\left(\exp \left(J_{w} K\right)-\exp \left(\frac{-J_{w}}{k_{d}}\right)\right)}\right.$ \\
\hline
\end{tabular}

Table 2: Impact of reverse salt diffusion and external concentration polarization on decreasing the specific power generation by the PRO process compared to ideal membrane (Model 1)

$\begin{array}{cclcccc}\text { Parameter } & \text { No. Modules } & \text { Source } & \text { Module 1 } & \text { Module 2 } & \text { Module 3 } & \text { Module 3 } \\ \text { CP+RSD+CPe } & 2 & \text { DS-SW } & 51 \% & 32.5 \% & - & - \\ \text { Model 1 vs. } & 2 & \text { DS-ROB } & 53 \% & 32 \% & - & - \\ \text { Model 2 } & 4 & \text { SW-RW } & 26 \% & 21 \% & 18 \% & 17 \% \\ & 4 & \text { ROB-WW } & 30 \% & 23 \% & 21 \% & 20 \% \\ \text { CP+CPe } & 2 & \text { DS-SW } & 45 \% & 23 \% & - & - \\ \text { Model 1 vs. } & 2 & \text { DS-ROB } & 47 \% & 24 \% & - & - \\ \text { Model 3 } & 4 & \text { SW-RW } & 25 \% & 22 \% & 17 \% & 16 \% \\ & 4 & \text { ROB-WW } & 19 \% & 14 \% & 12 \% & 11 \% \\ \text { RSD } & 4 & \text { DS-SW } & 11.5 \% & 12 \% & 13 \% & 13.4 \% \\ \text { Model 2 vs. } & 4 & \text { DS-ROB } & 12 \% & 11 \% & 10 \% & 9.5 \% \\ \text { Model 3 } & 4 & \text { SW-RW } & 1.5 \% & <1.0 \% & <1.0 \% & <1.0 \% \\ & 4 & \text { ROB-WW } & 13.4 \% & 10.5 \% & 10 \% & 10.5 \% \\ \text { CPe } & 4 & \text { DS-SW } & 5.5 \% & 5 \% & 5.3 \% & 5.5 \% \\ \text { Model 2 vs. } & 4 & \text { DS-ROB } & 8 \% & 8 \% & 4 \% & 3 \% \\ \text { Model 4 } & 4 & \text { SW-RW } & 1.5 \% & 2.5 \% & 3.7 \% & 3 \% \\ & 4 & \text { ROB-WW } & 1.4 \% & 3.5 \% & 3.5 \% & 3 \%\end{array}$




\section{Feasibility and practical application of osmotic power plants}

The general outlook of utilizing osmotic energy for electric power generation is optimistic, and several studies have investigated this technique as a new approach for renewable power generation benefiting from the latest advancements in the membrane manufacturing industry [11-12, 25-27]. However, these studies ignored the process requirements and limitations and focused mainly on the development of a suitable membrane and draw solution for a successful PRO process. In reality, the PRO process may be unable to generate sufficient energy owing to energy losses, process requirements and low osmotic energy of the salinity grdient. Energy losses include the energy lost in the pressure exchanger (PX), a limited pump efficiency, and membrane inefficiency, such as concentration polarization and reverse salt diffusion, which adversely affect the energy extracted by the PRO process. The process requirements include the energy needed for the treatment of the feed and draw solution and the pumping of the solutions to the PRO plant. These energy inputs should be considered to understand the capability of PRO for power generation from salinity-gradient resources.

According to equation 8, the maximum specific energy in the PRO process for the DS-SW, DS-ROB, SW-RW, and ROB-WW salinity gradients are $1.17 \mathrm{kWh} / \mathrm{m}^{3}, 0.79 \mathrm{kWh} / \mathrm{m}^{3}, 0.19$ $\mathrm{kWh} / \mathrm{m}^{3}$, and $0.39 \mathrm{kWh} / \mathrm{m}^{3}$, respectively [Table 3]. These maximum specific energies can only be achieved in an ideal PRO process; i.e. ignoring the effects concentration polarization and RSD. For non ideal PRO process, the impact of CP and RSD should be considered in the calculations of the specific energy generation. Furthermore, we assumed the efficiency of PX is $98 \%$, and the salt leakage in the PX was assumed to be insignificant. Table 3 shows the energy inputs, energy losses due to PX, and energy output by the PRO process. The pretreatment energy varied depending on the type of draw and feed solutions. For the DSSW salinity gradient, the pretreatment energy of SW reverse osmosis (RO) varies between 0.3 and $1 \mathrm{kWh} / \mathrm{m}^{3}$ depending on the technology [19, 20]. Previous studies demonstrated that PRO is more resistant to fouling than RO and proposed that the pretreatment energy ranges from 0.1 to $0.4 \mathrm{kWh} / \mathrm{m}^{3}$ [13]. Conservatively, we assumed that a minimum RO SW pretreatment energy of $0.3 \mathrm{kWh} / \mathrm{m}^{3}$ was applied to the SW feed solution and the DS draw solution. The DS-ROB salinity-gradient resource requires pretreatment only for the DS draw solution, as the ROB has already been treated for the RO plant. In the case of DS-SW salinity gradient, the pretreatment energy for the DS draw solution was assumed to be equal to that for the minimum RO SW pretreatment, i.e., $0.3 \mathrm{kWh} / \mathrm{m}^{3}$. The ROB-WW salinity gradient does not require pretreatment for the ROB draw solution, but feed WW requires pretreatment before the PRO process. WW is generally pretreated for the removal of organic and particulate matter before being discharged into the marine environment; the pretreatment energy applied to an RO feed is assumed to be between 0.1 and $0.2 \mathrm{kWh} / \mathrm{m}^{3}$ [28]. We assumed that the low WW pretreatment energy; i.e. $0.1 \mathrm{kWh} / \mathrm{m}^{3}$, was applied to the PRO membrane process because of its low fouling propensity compared with the RO SW pretreatment. For the SW-RW salinity-gradient resource, the pretreatment energy for SW draw solution was $0.3 \mathrm{kWh} / \mathrm{m}^{3}$. The pretreatment energy for RW is between 0.15 and 0.3 $\mathrm{kWh} / \mathrm{m}^{3}$; we assumed that the lower value of $0.15 \mathrm{kWh} / \mathrm{m}^{3}$ would satisfy the PRO process [19]. Further to the pretreatment energy, the energy for pumping from the source to the PRO plant was proposed to be between 0.02 and $0.05 \mathrm{kWh} / \mathrm{m}^{3}$ [29]. Pressure of approximately 1 bar was assumed for pumping the feeds from the source to the PRO plant, 
and the pumping energy was $0.03 \mathrm{kWh} / \mathrm{m}^{3}$. For the DS-ROB and ROB-WW salinity gradients, the pumping energy applies to the feed solution only, as we assumed that ROB was pumped directly from the RO to the PRO plant. Practically, ROB is slightly pressurized after leaving the energy-recovery device in the RO plant [30]. The pumping energy in the module energy was proposed to range from 0.05 to $0.1 \mathrm{kWh} / \mathrm{m}^{3}$ [22]. In this study, we assumed that a pumping pressure of 1.5 bar was likely to be sufficient for pumping the feed and draw solutions into the PRO module; the equivalent pumping energy was $0.05 \mathrm{kWh} / \mathrm{m}^{3}$. The efficiency of PX is $98 \%$; hence, a $2 \%$ energy loss occurs during the exchange process; the resulting energy loss is between 0.008 and $0.059 \mathrm{kWh} / \mathrm{m}^{3}$ [Table 3].

Table 3: Energy losses, energy inputs, and energy output for the PRO process

\begin{tabular}{lcccc}
\multicolumn{1}{c}{ Process Description } & DS-SW & DS-ROB & ROB-WW & SW-RW \\
Pretreatment & 0.3 & 0.15 & 0.05 & 0.225 \\
Pumping from source & 0.03 & 0.015 & 0.015 & 0.03 \\
Pumping in module & 0.05 & 0.05 & 0.05 & 0.05 \\
Loss in PX & 0.059 & 0.051 & 0.016 & 0.008 \\
Total energy input & $\mathbf{0 . 4 3 9}$ & $\mathbf{0 . 2 6 6}$ & $\mathbf{0 . 1 3 1}$ & $\mathbf{0 . 3 1 3}$ \\
PRO energy output & $\mathbf{0 . 6 5 9}$ & $\mathbf{0 . 4 8 2}$ & $\mathbf{0 . 1 5 2}$ & $\mathbf{0 . 0 6 1}$ \\
Maximum specific Energy in PRO & $\mathbf{1 . 1 7}$ & $\mathbf{0 . 7 9}$ & $\mathbf{0 . 3 9}$ & $\mathbf{0 . 1 9}$
\end{tabular}

The specific energy generation in the PRO process and the total energy input (including the energy for pretreatment, pumping, and losses, as shown in Table 3) were estimated for the salinity-gradient resources in Table 2 . Figure 4 shows the specific energy output and the total energy input during the PRO process for different salinity-gradient resources. The SWRW salinity gradient produced $0.061 \mathrm{kWh} / \mathrm{m}^{3}$ using four-module PRO system, whereas the total energy input during the PRO process was $0.313 \mathrm{kWh} / \mathrm{m}^{3}$ [Figure 4]; i.e. power generation in the PRO process was only $19 \%$ of the total energy input. The maximum specific energy of the SW-RW salinity gradient was $0.19 \mathrm{kWh} / \mathrm{m}^{3}$; this represents the maximum specific energy of an ideal PRO process operating in a counter-current mode at $P=\Delta \pi / 2$. Figure 5 shows that the total energy input of the SW-RW salinity gradient is 1.5 times more than the maximum specific energy; $0.19 \mathrm{kWh} / \mathrm{m}^{3}$. Therefore, $\mathrm{SW}$-RW salinity gradient is not appropriate for power generation in the PRO process. on the other hand, the maximum specific energy of the DS-ROB and ROB-WW salinity gradients was 3 times larger than the total energy input while it was 2.5 times larger than the total energy input of the DS-SW salinity gradient. Only $39 \%$ of the maximum specific energy of the ROB-WW salinity gradient was extracted in the PRO process. The specific energy yield of the ROB-WW salinity-gradient resource was $0.152 \mathrm{kWh} / \mathrm{m}^{3}$ and the total energy input was $0.131 \mathrm{kWh} / \mathrm{m}^{3}$. For the DS-ROB salinity-gradient resource, the specific energy of the PRO process, 0.482 $\mathrm{kWh} / \mathrm{m}^{3}$, was equal to $61 \%$ of the maximum specific energy. The energy yield of the DS-ROB salinity gradient was 1.8 times more than the total energy input, indicating the potential of this salinity gradient for application in osmotic power plants. One of the advantages of this salinity-gradient resource is the low pretreatment cost, as the ROB feed solution does not require pretreatment. The pretreatment energy of the DS-SW salinity gradient was higher than those of the other salinity gradients (Table 3). Yet, the specific energy yield of the PRO process was 1.5 times more than the total energy input. More than $56 \%$ of the maximum 
specific energy was recovered in the PRO process for the DS-SW salinity gradient. Using an advanced PRO module would further improve the performance of PRO process and increases the energy recovered from salinity gradients.

For a given PRO membrane, the feasibility of the osmotic power plant relies entirely on the type of salinity gradient and membrane efficiency. The results show that the total energy input varies with respect to the type of the salinity gradient and that most of that energy was consumed in the pretreatment process. DS coupling with SW or ROB was the most promising salinity-gradient resource and has potential for power generation. However, a multi-module PRO process would be needed to generate a useful amount of energy since a single PRO module was not able to generate enough energy to cover the total energy input. Current PRO modules such as Toyobo hollow-fiber PRO membrane offer up to $700 \mathrm{~m}^{2}$ of membrane area, which makes it a candidate for the PRO process, but its tolerance to a hydraulic feed pressure does not exceed 30 bar. Energy yield of the ROB-WW salinity gradient was more promising than the $S W-W W$ salinity gradient; the total energy input for the ROB-WW was lower than that for SW-RW because that the ROB draw solution requires no pretreatment. According to this study, the maximum specific energy of salinity gradient resource should be equal to that of the ROB-WW salinity gradient to achieve a feasible PRO process. In general, the ROB-WW salinity gradient is particularly important because of the abundance of draw solution from the RO desalination plant ease of coupling with pretreated WW stream in the PRO process. The maximum hydraulic pressure for the ROB-WW salinity gradient was 28 bar, which is within the range of Toyobo hollow fiber PRO module, which was tested in the Mega-Ton Project. The main concern revealed by this study regarding the ROB-WW salinity gradient is that the net power generation is low because of the energy losses due to pumping and pretreatment. Furthermore, the ROB-WW salinity gradient required four PRO modules, referring to the fact that a large number of membrane modules are needed to harvest the energy of the salinity gradient. One strategy for increasing the energy yield of the ROB-WW salinity gradient is increasing the number of PRO modules to five. This increased the specific energy generation by $6 \%$ (to $0.161 \mathrm{kWh} / \mathrm{m}^{3}$ ). However, this improvement is insignificant but can be further enhanced by applying more concentrated brine, such as the RO brine of SW from the Gulf water in the Middle East. Dual-stage PRO is an option for increasing the energy yield of the PRO process $[6,21]$. 


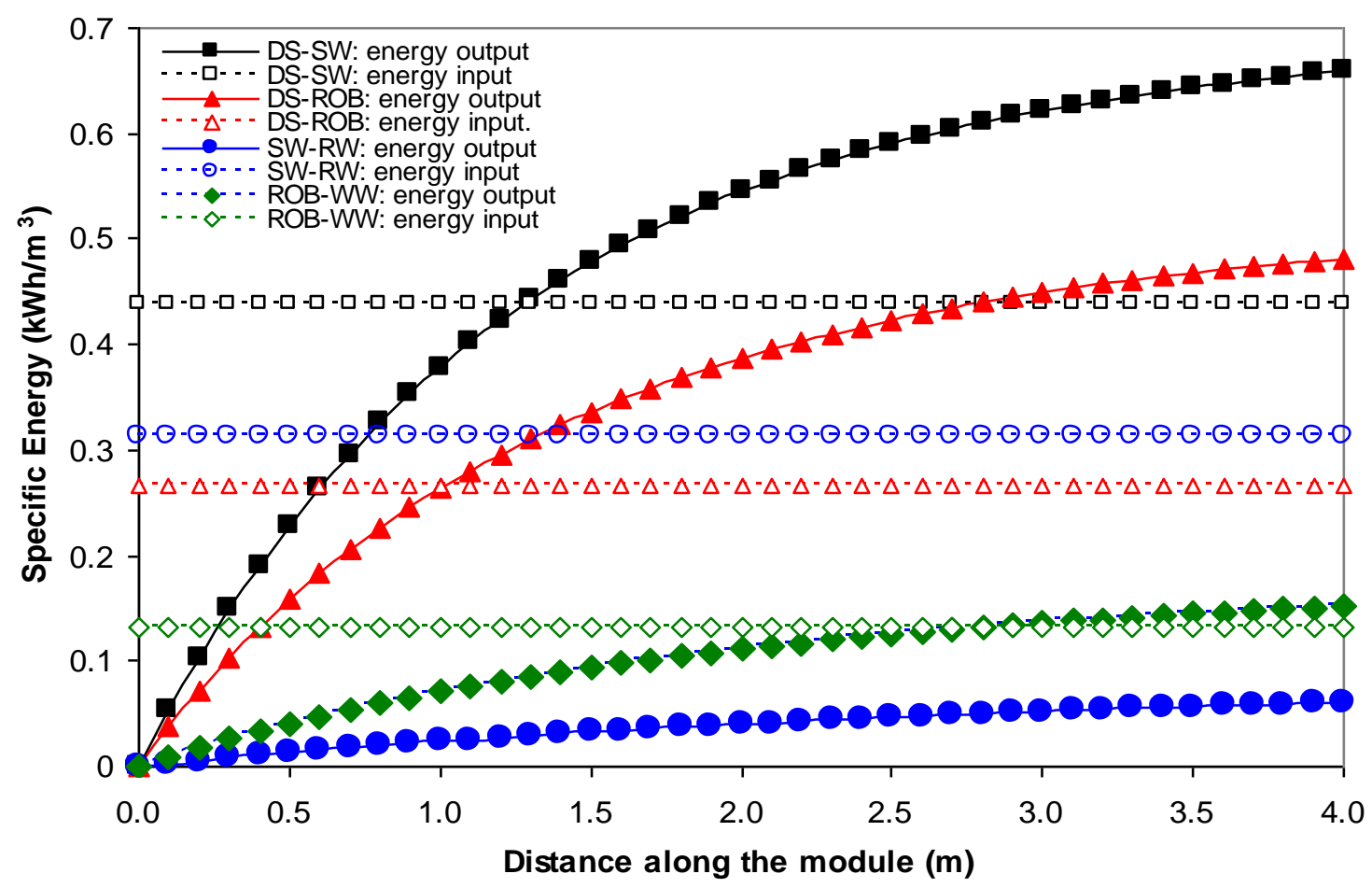

Figure 4: Specific energy generation in the PRO for different salinity-gradient resources and the total energy required, including the energy for pretreatment and feed and draw solution pumping and the energy loss in PX. The energy losses due to membrane inefficiencies, including the concentration polarization and reverse salt diffusion, were considered in the calculations of the power generation by the PRO process

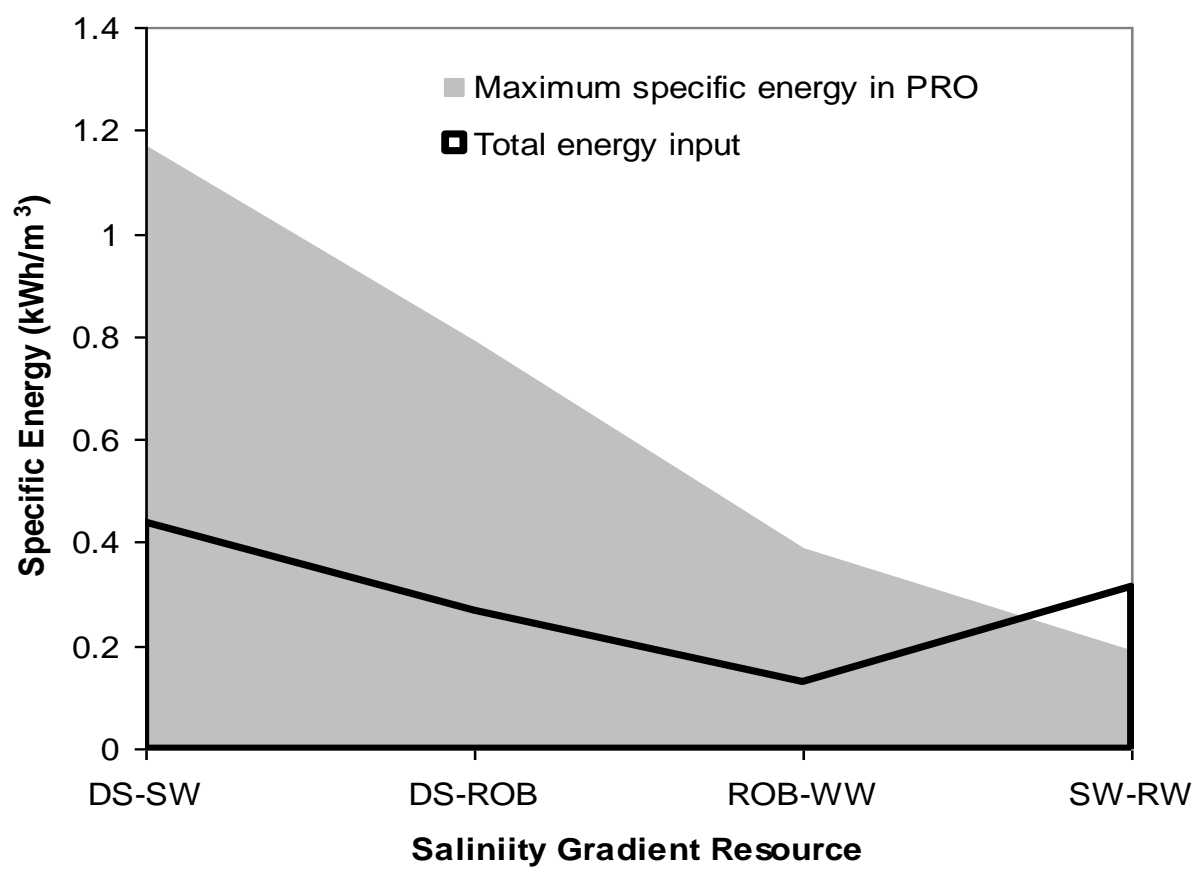

Figure 5: Maximum specific energy in PRO and total energy input for DS-SW, DS-ROB, ROBWW and SW-RW salinity gradient resources 


\section{Conclusion:}

The study highlighted the feasibility of the PRO process for power generation from different types of salinity-gradient resources. The PRO performance was dependent strongly on the type of salinity-gradient resource. Unfortunately, the maximum specific energy produced from the SW-RW salinity gradient was less than the total energy input which makes it unsuitable resource in the osmotic power plant. The energy yield of the DS-SW and DS-ROB salinity gradients at $P=\Delta \pi / 2$ was 0.659 and $0.482 \mathrm{kWh} / \mathrm{m}^{3}$, respectively, which is more than the energy input. With the current status of commercial PRO membranes, which withstand a maximum feed pressure of 30 bar, the DS draw solution cannot operate at the maximum power density. The ROB-WW draw solution has more potential for power generation than SW-RW because of the concentration of the RO brine and lack of pretreatment requirement. The net power generation for ROB-WW salinity gradient was greater than the total energy input, with the potential to be increased by reducing the losses due to membrane imperfections. Concentration polarization (CP) is the major technical drawback responsible for energy losses followed by reverse salt diffusion (RSD) and external resistance at the support layer (CPe). Future research should focus on the development of a suitable PRO membrane with high permeability, salt rejection, and withstand high hydraulic pressure. The outcomes of this study can be benchmarked in the future research for improving the performance of PRO process in terms of membrane characteristics and process design to maximize the energy output.

\section{Acknowledgement}

The author expresses gratitude to the School of Civil and Environmental Engineering of the University of Technology in Sydney, the European Commission (DG for Research \& Innovation) for its financial support in the EU 7th Framework Program SFERA-II project (Grant Agreement no. 312643), and the Public Authority for Applied Education and Training at Kuwait for the assistance with the study.

\section{References:}

[1] S. Loeb, F. Van Hessen, D. Shahaf, Production of energy from concentrated brines by pressure-retarded osmosis: II. Experimental results and projected energy costs, J. Membr. Sci., V 1(1976), 249-269.

[2] Ali Altaee, G. Millar, G. Zaragoza, Integration and Optimization of Pressure Retarded Osmosis with Reverse Osmosis for Power Generation and High Efficiency Desalination, Energy, 103 (2016), 110-118

[3] Ali Altaee, Adel Sharif, Pressure retarded osmosis: advancement in the process applications for power generation and desalination, Desalination, V 356 (2015), 31-46

[4] Endre Nagy, A general, resistance-in-series, salt-and water flux models for forward osmosis and pressure-retarded osmosis for energy generation, Journal of Membrane Science, V 460 (2014), 71-81.

[5] Nhu-Ngoc Bui, Jason T. Arena, Jeffrey R. McCutcheon, Proper accounting of mass transfer resistances in forward osmosis: Improving the accuracy of model predictions of structural parameter, Journal of Membrane Science, V 492 (2015), 289-302 
[6] Ali Altaee, Patricia Palenzuela, Guillermo Zaragoza, Adnan Alhathal AlAnezi, Single and Dual Stage Closed-Loop Pressure Retarded Osmosis for Power Generation: Feasibility and Performance, Applied Energy, V 191, (2017), 328-345

[7] Hyung Won Chung, Leonardo D. Banchik, Jaichander Swaminathan, John H. Lienhard V, On the present and future economic viability of stand-alone pressure-retarded osmosis, Desalination, V 408 (2017), 133-144.

[8] Keiichiro Saito, Morihiro Irie, Shintaro Zaitsu, Hideyuki Sakai, Hidechito Hayashi \& Akihiko Tanioka, Power generation with salinity gradient by pressure retarded osmosis using concentrated brine from SWRO system and treated sewage as pure water, Desalination and Water Treatment, V 41 (2012), 114-121.

[9] M. Kurihara, T. Sasaki, The Most Advanced Membrane Analysis and the Save-Energy Type Membrane-Low-Pressure Seawater Reverse Osmosis Membrane Developed by "Megaton Water System" Project, Reference Module in Chemistry, Molecular Sciences and Chemical Engineering, 2017

[10] Thor Thorsen, Torleif Holt, The potential for power production from salinity gradients by pressure retarded osmosis, Journal of Membrane Science, V 335 (2009), 103-110.

[11] Chang Kim, Menachem Elimelech, Potential of osmotic power generation by pressure retarded osmosis using seawater as feed solution: Analysis and experiments, Journal of Membrane Science, Volume 429, 15 February 2013, Pages 330-337.

[12] Jonathan Maisonneuve, Claude B. Laflamme, Pragasen Pillay, Experimental investigation of pressure retarded osmosis for renewable energy conversion: Towards increased net power, Applied Energy, V 164 (2016), 425-435

[13] Anthony P. Straub, Akshay Deshmukh and Menachem Elimelech, Pressure-retarded osmosis for power generation from salinity gradients: is it viable?, Energy \& Environmental Science, V 9 (2016), 31-48

[14] Stein Erik Skilhagen, Dr. Rolf Jarle Aaberg, Osmotic power - Power production based on the osmotic pressure difference between fresh water and sea water, Owemes 2006, 20-22 April. Citavecchia, Italy.

[15] Ali Altaee, Guillermo Zaragoza, Enrico Drioli, John Zouh, Evaluation the Potential and Energy Efficiency of Dual Stage Pressure Retarded Osmosis Process, Applied Energy, V 199 (2017), 359-369.

[16] Chun Feng Wan, Tai-Shung Chung, Osmotic power generation by pressure retarded osmosis using seawater brine as the draw solution and wastewater retentate as the feed. Journal of Membrane Science, Volume 479, 1 April 2015, Pages 148-158

[17] Ali Altaee, Adel Sharif, Guillermo Zaragoza, Dual stage PRO process for power generation from different feed resources, European Desalination Conference, 10-14 May 2015 Palermo, Italy

[18] Ali Altaee, Adel Sharif, More energy by dual stage PRO process for power generation from concentrated salinity gradient, Desalination for the Environment: Clean Water and Energy, Rome, 22-26 May 2016.

[19] G.K. Pearce, UF/MF pre-treatment to RO in seawater and wastewater reuse applications: a comparison of energy costs, Desalination, V 222 (2008) 66-73

[20] C. Fritzmann, J. Lo"wenberg, T. Wintgens and T. Melin, State-of-the-art of reverse osmosis desalination, Desalination, 2007, 216, 1-76.

[21] Ali Altaee, Guillermo Zaragoza, Adel Sharif, Pressure Retarded Osmosis for Power Generation and Seawater Desalination: Performance Analysis, Desalination, V 344 (2014), 108-115. 
[22] Shihong Lin, Anthony P. Straub and Menachem Elimelech, Thermodynamic limits of extractable energy by pressure retarded osmosis, Energy \& Environmental Science, $\mathrm{V} 7$ (2014), 2706-2714

[23] Mostafa H. Sharqawy, Syed M. Zubair, John H. Lienhard V, Second law analysis of reverse osmosis desalination plants: An alternative design using pressure retarded osmosis, Energy, Volume 36, (2011), 6617-6626

[24] Yuan Xu, Xiaoyu Peng, Chuyang Y. Tang, Q. Shiang Fu, Shengzhe Nie, Effect of draw solution concentration and operating conditions on forward osmosis and pressure retarded osmosis performance in a spiral wound module, Journal of Membrane Science, V 348 (2010), 298-309.

[25] Endre Nagy, József Dudás, Imre Hegedüs, Improvement of the energy generation by pressure retarded osmosis, Energy, V 116, Part 2, (2016), 1323-1333

[26] Gang Han, Sui Zhang, Xue Li, Tai-Shung Chung, Progress in pressure retarded osmosis (PRO) membranes for osmotic power generation, Progress in Polymer Science, V 51, (2015), $1-27$

[27] Chun Feng Wan, Bofan Li, Tianshi Yang, Tai-Shung Chung, Design and fabrication of inner-selective thin-film composite (TFC) hollow fiber modules for pressure retarded osmosis (PRO), Separation and Purification Technology, V 172 (2017), 32-42

[28] R.D. Reardon, S.V. Paranjape, X.J. Foussereau, F.A. DiGiano, M.D. Aitken, J.H. Kim, S.-Y. Chong and R. Cramer, Water for Reuse: Membrane Treatment of 2ry Effluent for Subsequent Use WERF Final Report, North Carolina University, 2005.

[29] A. K. Plappally and J. H. Lienhard V, Energy requirements for water production, treatment, end use, reclamation, and disposal, Renewable Sustainable Energy Reviews., $\mathrm{V}$ 16 (2012), 4818-4848.

[30] Gude V.G., Energy consumption and recovery in reverse osmosis, Desalination and Water Treatment, 36 (2011) 239-260.

[31] N. Y. Yip, A. Tiraferri, W. A. Phillip, J. D. Schiffman, L. A. Hoover, Y. C. Kim, M. Elimelech, Thin-film composite pressure retarded osmosis membranes for sustainable power generation from salinity gradients, Environ. Sci. Technol. 45 (2011) 4360-4369. 